\title{
Haptoglobin protein and mRNA expression in psoriasis and its clinical significance
}

\author{
FU-JUN TIAN ${ }^{1}$, YING-YING ZHANG ${ }^{2}$, LI-QIAN LIU ${ }^{1}$, YING XIONG ${ }^{1}$, \\ ZONG-SHAN WANG ${ }^{1}$ and SHOU-ZHONG WANG ${ }^{1}$ \\ ${ }^{1}$ Department of Dermatology, Linyi People's Hospital; \\ ${ }^{2}$ Department of Burns Surgery, Yishui Central Hospital, Linyi, Shandong 276003, P.R. China
}

Received September 9, 2015; Accepted July 19, 2016

DOI: $10.3892 / \mathrm{mmr} .2016 .5672$

\begin{abstract}
The present study aimed to explore the association between haptoglobin protein and mRNA expression and psoriasis. A total of 138 patients with psoriasis that were undergoing therapy at Linyi People's Hospital (Linyi, China) between January 2011 and January 2015 were enrolled in the present study. The mRNA expression levels of haptoglobin were detected by in situ hybridization; immunohistochemistry was used to detect haptoglobin protein expression; and double-labeling immunofluorescence was used to count Langerhans cells; western blotting was also conducted to determine protein expression. A receiver operating characteristic (ROC) curve was generated to assess the diagnostic value of haptoglobin for psoriasis. Compared with the normal and negative control (NC) groups, the mRNA expression levels of haptoglobin were markedly increased in the experimental group $(\mathrm{P}<0.05)$. Haptoglobin protein expression was also markedly increased in the experimental group compared with in the normal and $\mathrm{NC}$ groups $(\mathrm{P}<0.05)$. Conversely, there was no significant difference in haptoglobin expression between the $\mathrm{NC}$ group and the normal group $(\mathrm{P}>0.05)$. The critical value of haptoglobin mRNA in the diagnosis of psoriasis was 2.93, and sensitivity and specificity were 91.3 and $73.6 \%$, respectively. The area under the ROC curve was 0.883 [95\% confidence interval $(\mathrm{CI})=0.837-0.929]$. The critical value of haptoglobin protein in the diagnosis of psoriasis was 0.995 , and sensitivity and specificity were 76.1 and $99.9 \%$, respectively. The area under the ROC curve was 0.926 (95\% CI=0.837-0.929). The present study demonstrated that the mRNA and protein expression levels of haptoglobin were increased in patients with psoriasis. Haptoglobin mRNA and protein expression
\end{abstract}

Correspondence to: Dr Li-Qian Liu, Department of Dermatology, Linyi People's Hospital, 27 Jiefang Road, Lanshan, Linyi, Shandong 276003, P.R. China

E-mail: liuliqian0907@163.com

Key words: haptoglobin, psoriasis, in situ hybridization, Langerhans cells, immunohistochemistry, double-labeling immunofluorescence, western blotting were closely associated with the occurrence of psoriasis; therefore, haptoglobin may be considered a promising novel clinical indicator for the diagnosis of psoriasis.

\section{Introduction}

Psoriasis is a chronic, proliferative and inflammatory skin disease, which typically affects individuals in their twenties, yet can occur at any age (1). The incidence of psoriasis in the European population is $2-3 \%$, whereas it only accounts for $\leq 0.1 \%$ in the Asian population, and is exceedingly rare in Africa (2). This long lasting disease is typically characterized by recurrent episodes of red, itchy and scaly patches of abnormal skin, which may also be sharply demarcated from the adjacent normal skin (3). There are five main types of psoriasis: Plaque, inverse, guttate, pustular and erythrodermic $(2,4)$. In particular, plaque psoriasis, which is also known as psoriasis vulgaris, makes up $\sim 90 \%$ of cases. It typically presents as red patches with white scales on top $(2,5,6)$. At present, psoriasis remains a serious, poorly understood disease. One hypothesis suggests that the occurrence of psoriasis is due to functional immaturity of keratinocytes induced by an inflammatory cascade in the dermis resulting from various immune cells (6). These immune cells, including dendritic cells, macrophages and $\mathrm{T}$ cells, move from the dermis to the epidermis and secrete inflammatory cytokines (7). Previous studies have reported that a defect in regulatory $\mathrm{T}$ cells may underlie this disease $(7,8)$. Therefore, $\mathrm{T}$ lymphocytes may have an important role in the occurrence of psoriasis.

Haptoglobin is a positive acute-phase reactant and plasma glycoprotein, which binds to free hemoglobin to form the hemoglobin-haptoglobin complex. Haptoglobin is known to be predominantly produced in the liver (9). Haptoglobin exerts anti-infectious effects, prevents iron loss and renal damage, regulates immune function, and defends against the oxidative effects of hemoglobin/iron $(10,11)$. Several studies have demonstrated that haptoglobin engages in various disease states, including lung cancer, pancreatic cancer, liver cancer, diabetes and prostate cancer (12-14). Condyloma acuminatum is one of the most common anogenital skin diseases (15). Previous studies have reported that haptoglobin may inhibit the functional maturation of Langerhans cell, and may therefore be involved in the immunoregulatory process $(16,17)$. 
Abnormal immune function is crucial for the development of psoriasis; therefore, haptoglobin expression and its regulatory mechanisms in psoriasis tissues may be of great significance. In addition, due to haptoglobin gene polymorphisms, haptoglobin has been investigated as a biomarker with regards to its correlation with disease (18). The present study aimed to examine the mRNA and protein expression levels of haptoglobin in psoriasis tissues, and to determine its clinical significance in psoriasis.

\section{Materials and methods}

Patients. A total of 138 patients with psoriasis (76 men and 62 women; mean age, $44.39 \pm 18.22$ years; age range, $13-75$ years) that were undergoing therapy at Linyi People's Hospital (Linyi, China) between January 2011 and January 2015 were enrolled in the present study. The duration of disease was 1-240 months (mean, 113.25 \pm 69.89 months). Lesional skin specimens from the patients with psoriasis were selected as experimental group samples, whereas normal-looking skin specimens from the experimental group within $2 \mathrm{~cm}$ of psoriasis were selected as negative control (NC) group samples. The inclusion and exclusion criteria for the present study were as follows: i) Patients with typical clinical manifestations of psoriasis vulgaris that was diagnosed by histopathology; ii) no systemic application of vitamin A acid and glucocorticoid within 4 weeks, and no local treatment within 2 weeks; iii) all individuals were unrelated; iv) patients with localized, pustular, erythrodermic and psoriatic arthritis were excluded; v) patients with atypical early clinical performance, those that failed to be definitively diagnosed, and those without sufficient diagnostic evidence were excluded; vi) patients with severe disorders, including cardiovascular diseases and cancer were excluded; vii) patients who were pregnant or breastfeeding were excluded; viii) patients who were reluctant to cooperate, or for whom there was incomplete clinical data were excluded. The normal group consisted of 106 normal human skin samples obtained from non-psoriatic patients (63 males and 43 females; mean age, $42.15 \pm 15.62$ years; age range, $21-70$ years) from the orthopedic surgery unit of the hospital, none of which suffered from immunological diseases or other systematic diseases. There were no statistical differences in age and gender between the experimental group and the normal group. The skin tissues were immediately embedded with Optimal Cutting Temperature (OCT) compound (Hede Biological Technology Co. Ltd., Beijing, China), and were maintained at $-70^{\circ} \mathrm{C}$ until further use. The study protocol was approved by the ethics committee of Linyi People's Hospital and informed consent was obtained from each patient.

In situ hybridization. An in situ hybridization kit was purchased from Wuhan Boster Biological Technology Ltd. (Wuhan, China). All specimens were fixed with $40 \mathrm{~g} / 1$ paraformaldehyde, and glass slides were processed with poly-L-lysine. To prevent degradation of the RNase enzyme, all reagents were prepared in sodium acid pyrophosphate (DEPC) solution. Briefly, tissues were fixed by paraffin embedding, and then sections $(12 \mu \mathrm{m})$ were prepared using a cryostat at $-25^{\circ} \mathrm{C}$, and the sections were incubated in $3 \mathrm{ml} / \mathrm{l} \mathrm{H}_{2} \mathrm{O}_{2}$ solution for 10 min following dewaxing and hydration. Subsequently, the samples were washed with DEPC solution for $6 \mathrm{~min}$ and were digested in proteinase $\mathrm{K}$ solution for $30 \mathrm{~min}$ at $37^{\circ} \mathrm{C}$ to remove surface proteins that could impede the combination of probes. The samples were then rinsed in phosphate-buffered saline (PBS) and DEPC solution for $6 \mathrm{~min}$, respectively. The slides were treated with $20 \mu \mathrm{l}$ pre-hybridization solution and were incubated at $42^{\circ} \mathrm{C}$ for $2 \mathrm{~h}$. The sequence of the synthesized haptoglobin oligonucleotide probes was: 5'-TTCTACTGA TGTTATCTCCAGGATGCTGTA-3' (3'-marked by digoxin). Subsequently, the samples were hybridized at $42^{\circ} \mathrm{C}$ for $22 \mathrm{~h}$, and were washed with $2 x S S$ and $1 x$ SSC for 15 min, separately. The samples were further incubated in sheep serum blocking buffer at $37^{\circ} \mathrm{C}$ for $30 \mathrm{~min}$, biotin-anti-digoxin antibody at $37^{\circ} \mathrm{C}$ for $1 \mathrm{~h}$, and horseradish peroxidase-conjugated streptomycin at $37^{\circ} \mathrm{C}$ for $30 \mathrm{~min}$. Finally, the samples were stained with diaminobenzidine and were counterstained with nuclear fast red. Negative control samples were treated with PBS, rather than hybridization solution, and normal liver tissue sections were used as positive controls. Bright orange-red staining in the cytoplasm was considered to be positive staining. The staining was analyzed by MetaMorph Microscopy Automation \& Image Analysis Software (V4.6; Molecular Devices, LLC, Sunnyvale, CA, USA). According to the image gray scale results, there were five staining grades: i) Negative (-), no staining, gray value $>130$; ii) weak $( \pm)$, slight staining, gray value $125-130$; iii) positive $(+)$, shallow staining, gray value 115-125; moderately strong $(++)$, deep staining, gray value $105-115$; very strong $(+++)$, deeper staining, gray value $<105$.

Reverse transcription-polymerase chain reaction (RT-PCR). Tissues were weighed and then put into a mortar (precooled with liquid nitrogen) for homogenization. Tissues (100 mg) were added to $1 \mathrm{ml}$ TRIzol reagent (Invitrogen; Thermo Fisher Scientific, Inc., Waltham, MA, USA) for the extraction of total RNA. The RT system consisted of the following reagents: 10X RT buffer $(1 \mu \mathrm{l}), \mathrm{MgCl}_{2}(25 \mathrm{mM}), 2 \mu \mathrm{l} \mathrm{dNTP}$ complex $(10 \mathrm{mM}, 1 \mu \mathrm{l})$, reverse transcriptase $(0.5 \mu \mathrm{l})$, RNasin Inhibitor $(0.25 \mu \mathrm{l})$, Random 9 mers $(0.5 \mu \mathrm{l})$, total RNA $(\leq 500 \mathrm{ng}, 2 \mu \mathrm{l})$; the system was diluted with $0.1 \%$ DEPC-treated water to a final volume of $10 \mu \mathrm{l}$. RT was conducted under the following conditions: $30^{\circ} \mathrm{C}$ for $10 \mathrm{~min}$, $42^{\circ} \mathrm{C}$ for $30 \mathrm{~min}$ and $99^{\circ} \mathrm{C}$ for $5 \mathrm{~min}$. The PCR system was 5X PCR buffer $(10 \mu 1)$, Taq DNA polymerase $(0.25 \mu 1)$, forward primer and reverse primer (both 20 pmol, $0.5 \mu \mathrm{l}$ ) with $\beta$-actin as an internal control (Table I); the system was diluted with $0.1 \%$ DEPC-treated water to a final volume of $50 \mu 1$. The two pairs of primers and other PCR reagents were obtained from Takara Biotechnology Co., Ltd. (Dalian, China). The PCR cycling conditions were as follows: $94^{\circ} \mathrm{C}$ for $5 \mathrm{~min}, 94^{\circ} \mathrm{C}$ for $1 \mathrm{~min}, 50^{\circ} \mathrm{C}$ for $1 \mathrm{~min}$ and $72^{\circ} \mathrm{C}$ for $1 \mathrm{~min}$ (30 cycles), and finally $72^{\circ} \mathrm{C}$ for $5 \mathrm{~min}$. Subsequently, a $1.5 \%$ agarose gel was placed into a $0.5 \mathrm{X}$ TBE electrophoresis chamber, the amplified products $(10 \mu \mathrm{l})$ were added, and the gel was subsequently stained with ethidium bromide. Finally, images were captured using a UV-gel imaging system (UVP GDS 8000; UVP, Inc., Upland, CA, USA). The gray value of each DNA amplified band was recorded, the ratio of the gray value of each target DNA amplified fragment and the gray value of the $\beta$-actin amplified fragment was regarded as a semi-quantitative index of each target gene mRNA. 
Table I. Primer sequences and amplification product length.

Upstream

Downstream

$\beta$-actin

Upstream

Downstream
5'-ACCTTAAACGACCAGAAGCAATGG-3'

5'-AGCCAGACACGTAGCCCCACACG-3'

5'-GTGGGCCGCTCTAGGCACCAA-3'

5'-CTCTTTGATGTCACGAVGATTTC-3'

Table II. mRNA expression of Haptoglobin as determined by in situ hybridization.

\begin{tabular}{|c|c|c|c|c|c|c|}
\hline \multirow[b]{2}{*}{ Group } & \multirow[b]{2}{*}{ Cases } & \multicolumn{5}{|c|}{ Staining intensity } \\
\hline & & - & \pm & + & ++ & +++ \\
\hline Normal & 106 & 0 & 33 & 56 & 17 & 0 \\
\hline Head and face & 29 & 0 & 0 & 22 & 7 & 0 \\
\hline Trunk & 45 & 0 & 8 & 34 & 3 & 0 \\
\hline Limbs & 32 & 0 & 25 & 0 & 7 & 0 \\
\hline Negative control & 138 & 0 & 18 & 120 & 0 & 0 \\
\hline Experimental & 138 & 0 & 0 & 13 & 112 & 13 \\
\hline
\end{tabular}

-, negative; \pm , weak; +, positive; ++, moderately strong; +++, very strong.

Table III. Hp ${ }^{+}-\mathrm{LC}, \mathrm{CDla}^{+}-\mathrm{LC}$ and $\mathrm{Hp}^{+}-\mathrm{LC} / \mathrm{Cdla}^{+}-\mathrm{LC}$ in the groups $(\bar{x} \pm \mathrm{s})$.

\begin{tabular}{lcccc}
\hline Group & Cases & $\mathrm{Hp}^{+}-\mathrm{LC}$ & CDla $^{+}-\mathrm{LC}$ & $\mathrm{Hp}^{+}-\mathrm{LC} / \mathrm{CDla}^{+}-\mathrm{LC}$ \\
\hline Normal & 106 & $2.44 \pm 1.99$ & $38.51 \pm 22.56$ & $6.91 \pm 5.01$ \\
Negative control & 138 & $15.17 \pm 9.57^{\mathrm{a}}$ & $66.69 \pm 21.71^{\mathrm{a}}$ & $27.78 \pm 23.20^{\mathrm{a}}$ \\
Experimental & 138 & $7.45 \pm 5.70^{\mathrm{a}}$ & $28.89 \pm 11.29^{\mathrm{a}}$ & $26.40 \pm 19.16^{\mathrm{a}}$ \\
\hline
\end{tabular}

Langerhans cells in the epidermis/mm. ${ }^{\mathrm{P}}<0.05$ vs. normal group. Hp, haptoglobin; LC, Langerhans cells.

Immunohistochemistry. The avidin-biotin complex (SABC) immunohistochemical method was used to detect haptoglobin in cells. An SABC immunohistochemical staining kit was purchased from Wuhan Boster Biological Technology Ltd. Skin samples were covered with OCT, and $6 \mu \mathrm{m}$ frozen sections were cut. After the slices were dewaxed and hydrated, they were incubated with $3 \% \mathrm{H}_{2} \mathrm{O}_{2}$ deionized water for 10 min to block endogenous peroxidase. Subsequently, mouse anti-human haptoglobin antibody (1:100 dilution; cat. no. ab13429; Abcam, Cambridge, UK) was incubated with the sections overnight at room temperature. The slices were washed with PBS for $5 \mathrm{~min}$, and a biotin-labeled secondary antibody (1:100; cat. no. ab99817; Abcam) was added and incubated at $37^{\circ} \mathrm{C}$ for $10 \mathrm{~min}$. The slices were washed for $5 \mathrm{~min}$, and incubated with SABC compounds at $37^{\circ} \mathrm{C}$ for $30 \mathrm{~min}$. At room temperature, the slices were stained with 3-amino-9-ethylcarbozole for 10-20 min, and rinsed with distilled water, counterstained with with hematoxylin for $30 \mathrm{sec}$ and the sections were observed under a light microscope. PBS $(0.01 \mathrm{~mol} / \mathrm{l})$ was used as a negative control.

Double-labeling immunofluorescence. Specimen sections $(6 \mu \mathrm{m})$ were immobilized in acetone at room temperature for $10 \mathrm{~min}$, and were then washed with PBS (0.05 mol/l; pH 7.2; 5 min $x 3$ washes). Sections were incubated in goat serum (1:20; Beijing ComWin Biotech Co., Ltd., Beijing, China), which was used as a blocking buffer, at $37^{\circ} \mathrm{C}$ for $20 \mathrm{~min}$. Subsequently, mouse anti-human haptoglobin (1:80) was added overnight at $4^{\circ} \mathrm{C}$, meanwhile, mouse $\operatorname{IgG}$ was used as an isotype control. Rhodamine-labeled goat anti-mouse IgG (1:80; Sigma-Aldrich; Merck Millipore, Darmstadt, Germany) was added at $37^{\circ} \mathrm{C}$ for $1 \mathrm{~h}$, and normal mouse serum (1:10; Hangzhou TopHere Tech Co. Ltd., Hangzhou, China) was added at $37^{\circ} \mathrm{C}$ for $20 \mathrm{~min}$. Fluorescein isothiocyanate-labeled mouse anti-human CDla (1:80; cat. no. ab780; Abcam) was added for $1 \mathrm{~h}$ at $37^{\circ} \mathrm{C}$. Images were visualized under a fluorescent microscope after 

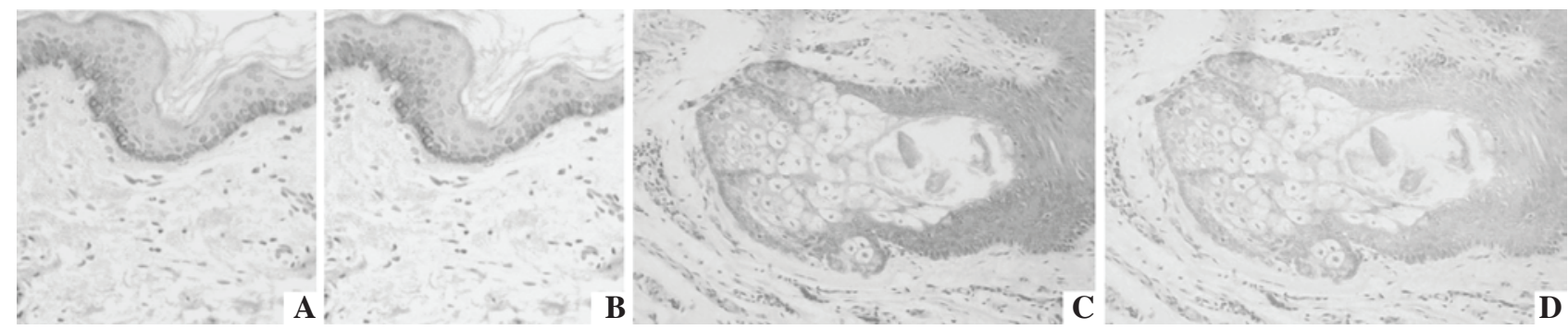

Figure 1. Haptoglobin mRNA expression was detected by in situ hybridization in the normal control group (aminoethylcarbazole staining; magnification, x200). (A) Haptoglobin mRNA expression in the epidermis. Red staining in the cytoplasm of keratinocytes indicated haptoglobin mRNA positivity. (B) Haptoglobin mRNA expression in the epidermis. (C) Haptoglobin mRNA expression in the sebaceous gland. Red staining in the cytoplasm of the sebaceous gland duct and epithelial cells indicated haptoglobin mRNA positivity. (D) Haptoglobin mRNA expression in the sebaceous gland.
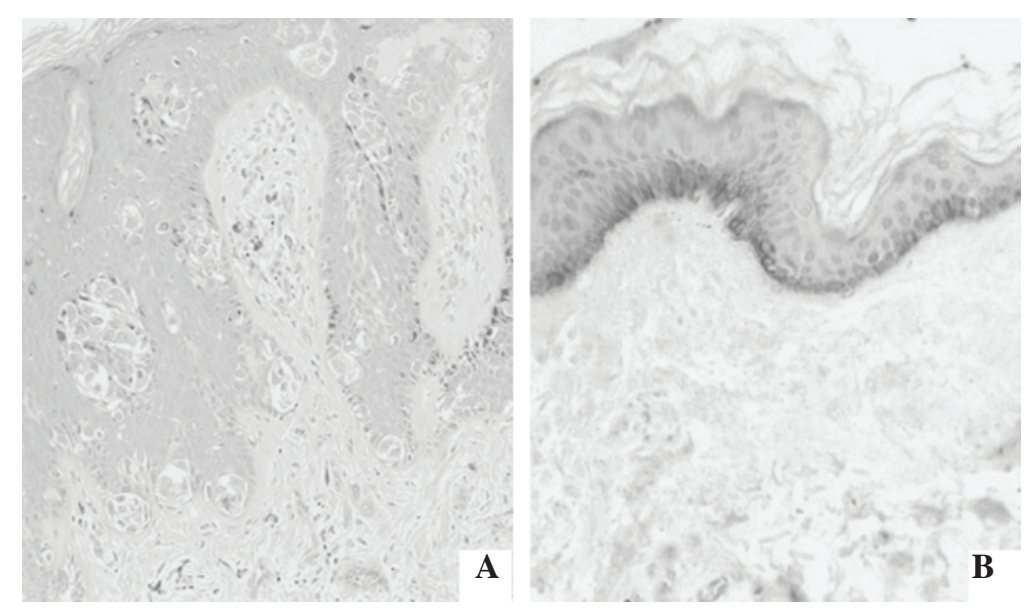

Figure 2. Haptoglobin mRNA expression in experimental group and negative control (NC) group as determined by in situ hybridization (aminoethylcarbazole). (A) Haptoglobin mRNA expression in keratinocytes of the experimental group (original magnification, x250; not counterstained with hematoxylin). Obvious red staining was detected in the cytoplasm of epidermal keratinocytes. (B) Haptoglobin mRNA expression in keratinocytes of the NC group (original magnification, x200; not counterstained with hematoxylin). Red staining was detected in the cytoplasm of epidermal keratinocytes.
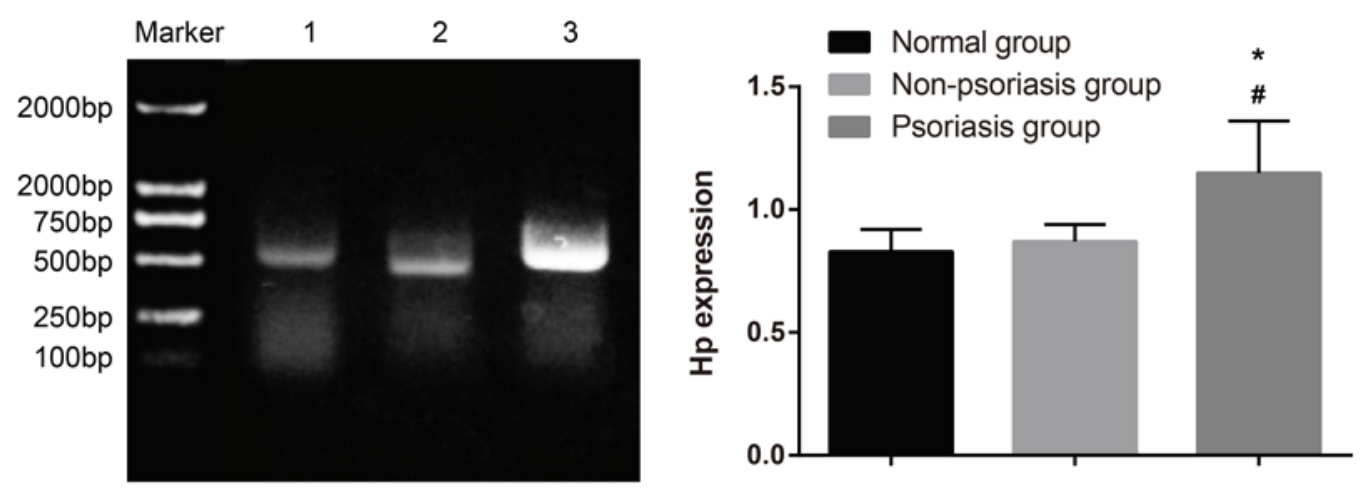

Figure 3. Hp mRNA expression.(A) Polymerase chain reaction products were separated on agarose gel. 1, normal group; 2, non-psoriasis group; 3, psoriasis group ${ }^{*} \mathrm{P}<0.05$ vs. normal group; ${ }^{*} \mathrm{P}<0.05$ vs. negative control group. Hp, haptoglobin.

samples were washed in PBS, and the number of Langerhans cells was counted.

Western blotting for haptoglobin. Total protein was extracted from the skin samples. Sterile scissors were used to cut tissue pieces and a tissue protein lysis solution (Roche Diagnostics, Basel, Switzerland) was added to the tissue and homogenized and ice-bathed for $3 \mathrm{~min}$ then maintained at $-20^{\circ} \mathrm{C}$ until further use. Sodium dodecyl sulfate-polyacrylamide gel electrophoresis ( $10 \%$ gel) was prepared, and protein concentrations were used to calculate loading quantities. After being mixed with loading buffer (1:1), the samples were incubated in a boiling water bath for 5 min before being loaded. In a $4^{\circ} \mathrm{C}$ water bath, the gel was run at $60 \mathrm{~mA}$ (constant current) for $1 \mathrm{~h}$. Subsequently, the gel was cut, the loading dye was removed, and the gel-membrane sandwich was run at $100 \mathrm{~V}$ (constant voltage) for $1 \mathrm{~h}$ at $4^{\circ} \mathrm{C}$ to transfer proteins to the polyvinylidene difluoride membrane. The membrane was 

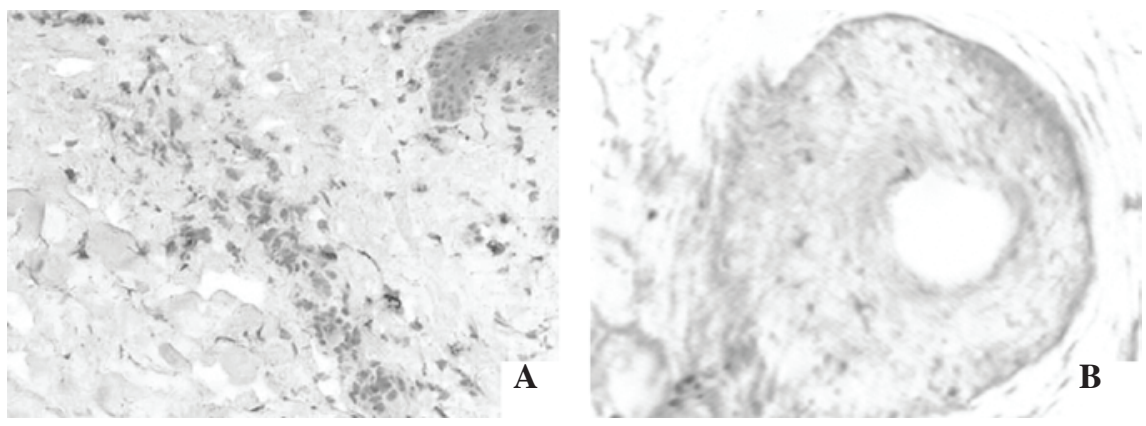

Figure 4. Haptoglobin immunohistochemical staining in the normal group (aminoethylcarbazole; original magnification, x400). (A) Haptoglobin immunohistochemical staining in the epidermis. (B) Haptoglobin immunohistochemical staining in a hair follicle. Red staining was detected in the cytoplasm of dendritic cells.
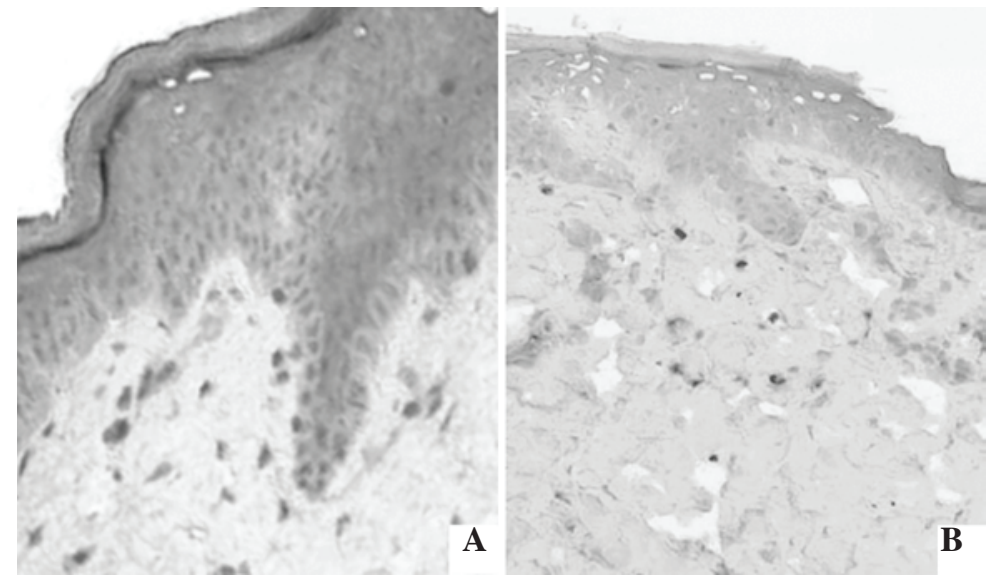

Figure 5. Haptoglobin immunohistochemical staining in the experimental and negative control (NC) groups. (A) Haptoglobin immunohistochemical staining in the experimental group (aminoethylcarbazole; original magnification, x250; not counterstained with hematoxylin). Obvious red staining was detected in the cytoplasm of epidermal keratinocytes. (B) Haptoglobin immunohistochemical staining in the NC group (aminoethylcarbazole; original magnification, x400). Haptoglobin was positive in most dendritic cells.

blocked in $5 \%$ skimmed milk for $2 \mathrm{~h}$ at $37^{\circ} \mathrm{C}$ or overnight at $4^{\circ} \mathrm{C}$. After blocking, the membrane was incubated with the primary antibodies (mouse anti-human haptoglobin; 1:1,000; cat. no. ab131236; Abcam), and was then incubated with the secondary antibody (biotin-labeled goat anti-mouse IgG; 1:10,000, cat. no. ab6785; Abcam) at $37^{\circ} \mathrm{C}$. Subsequently, the membrane was briefly rinsed, visualized using an enhanced chemlimuninescence kit, and was processed using an AlphaInnotech gel imaging system (ProteinSimple, San Jose, CA, USA). $\beta$-actin was used as the loading control (1:10,000; cat. no. ab8226; Abcam).

Statistical analysis. SPSS version 19.0 software (IBM SPSS, Armonk, NY, USA) was used to conduct statistical analyses. Data are presented as the mean \pm standard deviation. The comparison of average values among multiple groups was performed using one-way analysis of variance. The results of in situ hybridization were compared by chi-square test. F test was used for whole comparisons if there was homogeneity of variance and Bonferroni method was used for multiple comparisons; Welch test was used for whole comparison if there was no homogeneity of variance and Dunnett's T3 method was used for multiple comparisons. All statistical tests were two-sided. $\mathrm{P}<0.05$ was considered to indicate a statistically significant difference.

\section{Results}

mRNA expression levels of haptoglobin as determined by in situ hybridization. Weak to relatively strong $( \pm-++)$ expression of haptoglobin mRNA was detected, predominantly (+) in keratinocytes, hair follicles, sebaceous gland ducts, glandular epithelia and eccrine glands (Fig. 1). Out of the 29 skin samples from the head and face the results were as follows: $22(+), 7(++)$; of the 45 skin samples from the trunk the results were as follows: $8( \pm), 34(+), 3(++)$; and of the 32 skin samples from the limbs the results were as follows: $25( \pm), 7(++)$. No significant difference was determined between the different parts of the skin ( $\mathrm{P}>0.05$; Table II); and no expression was observed in fibroblasts and endothelial cells of the dermis. Haptoglobin mRNA was observed in the experimental and NC groups (Fig. 2). Compared with the normal group, haptoglobin mRNA expression was markedly increased in the experimental group (Table II; $\mathrm{P}<0.05$ ); however, no significant difference was detected between the $\mathrm{NC}$ and normal groups ( $\mathrm{P}>0.05)$. Compared with the NC group, haptoglobin mRNA expression was markedly increased in the experimental group (Table II; $\mathrm{P}<0.05$ ).

Results of RT-PCR. According to the RT-PCR results, haptoglobin mRNA expression was statistically different between 


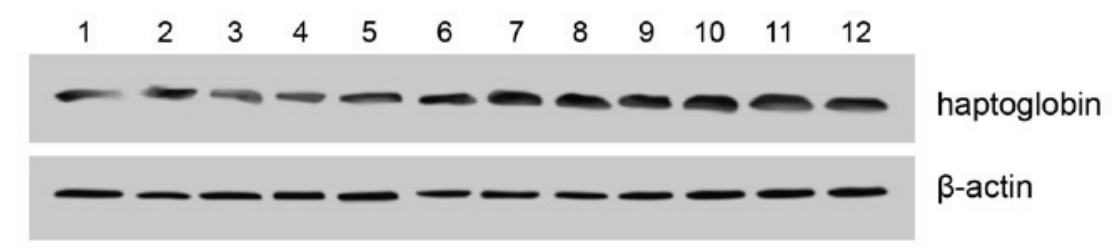

Figure 6. Haptoglobin expression in the normal, negative control and experimental groups, as determined by western blotting. Lanes 1-4, normal group; 5-9, negative control group; 10-12, experimental group.

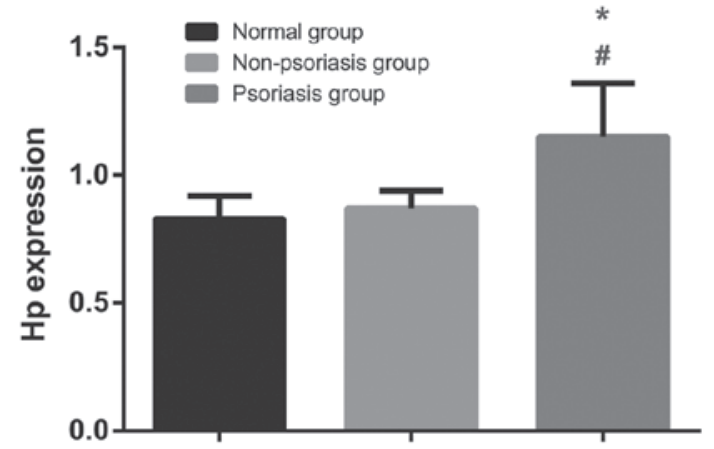

Figure 7. Haptoglobin (Hp) expression in psoriasis. ${ }^{*} \mathrm{P}<0.05$ vs. normal group; ${ }^{\#} \mathrm{P}<0.05$ vs. negative control group.

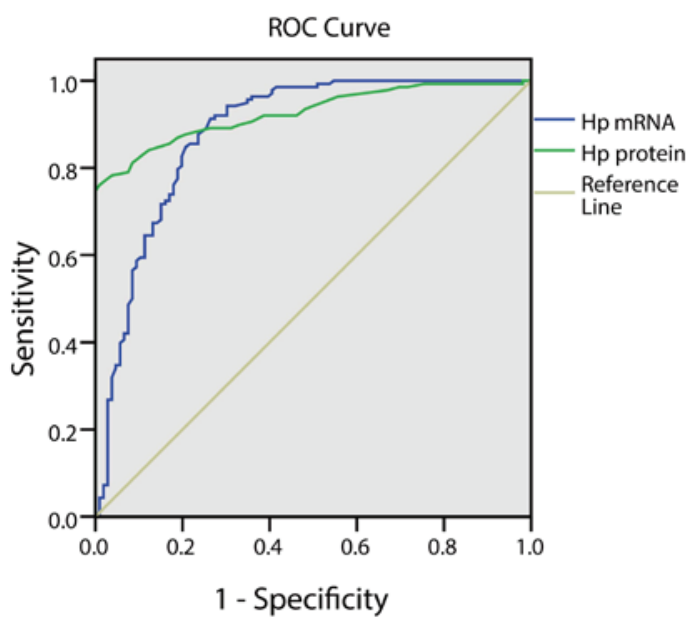

Figure 8. Haptoglobin (Hp) protein and mRNA expression for the diagnosis of psoriasis. ROC, receiver operating characteristic.

the groups $(\mathrm{F}=144.9 ; \mathrm{P}<0.001)$. The mRNA expression levels of haptoglobin were markedly higher in the experimental group compared with the normal group (Fig. 3; $\mathrm{P}<0.05$ ), whereas no statistically significant difference was detected in haptoglobin mRNA expression between the $\mathrm{NC}$ and normal groups $(\mathrm{P}>0.05)$. The mRNA expression levels of haptoglobin were significantly increased in the experimental group compared with the NC group (Fig. 3; $\mathrm{P}<0.05$ ).

Results of immunohistochemistry and double-labeling immunofluorescence. In the normal control group, the linear density of positive cells in the epidermis and hair follicles was not markedly different (Fig. 4A and B). In the experimental group, haptoglobin expression with heterogeneous distribution was detected in the keratinocytes, whereas no haptoglobin expression was detected in the keratinocytes of the NC and normal control groups. Some haptoglobin ${ }^{+}$dendritic cells were detected in all three groups. In the experimental group, small dendritic cells were detected in the middle-upper epidermis, and the dendrites were short and thick (Fig. 5A). However, in the other two groups, dendritic cells were mainly distributed in the middle and lower segments of the epidermis, and dendrites were thin and long (Fig. 5B). Double-labeling immunofluorescence demonstrated that all haptoglobin ${ }^{+}$dendritic cells were confirmed to be $\mathrm{CDla}^{+}$Langerhans cells, while only some of which were haptoglobin positive cells. Compared with the normal control group, the ratio of Haptoglobin ${ }^{+}$Langerhans cells to total Langerhans cells was markedly increased in the experimental and NC groups (Table III; F=253.1; $\mathrm{P}<0.001$ ).

Results of western blotting. The protein expression levels of haptoglobin in the three groups are presented in Fig. 6, as determined by western blotting. Haptoglobin expression was significantly increased in the experimental group compared with in the normal group $(1.15 \pm 0.21$ vs. $0.83 \pm 0.09 ; \mathrm{P}<0.05)$, whereas there was no statistically significant difference between the $\mathrm{NC}$ group and the normal group $(0.87 \pm 0.07$ vs $0.83 \pm 0.09 ; \mathrm{P}>0.05)$. Furthermore, haptoglobin was highly expressed in the experimental group compared with in the NC group (Fig. 7; P<0.001).

Haptoglobin protein and mRNA expression for the diagnosis of psoriasis. Using the clinical expression level of haptoglobin protein and mRNA as a standard, an ROC curve was generated to assess the diagnostic value of haptoglobin for psoriasis. In addition, the curve determined the sensitivity and specificity of haptoglobin protein and mRNA expression for the diagnosis of psoriasis. The critical value of haptoglobin mRNA expression in the diagnosis of psoriasis was 2.93 , whereas sensitivity and specificity were 91.3 and $73.6 \%$, respectively. The area under the ROC curve was $0.883,95 \% \mathrm{CI}=0.837-0.929$. The critical value of haptoglobin protein expression in the diagnosis of psoriasis was 0.995 , whereas sensitivity and specificity were 76.1 and $99.9 \%$, respectively. The area under the ROC curve was $0.926,95 \% \mathrm{CI}=0.837-0.929$ (Fig. 8 ).

\section{Discussion}

At present, psoriasis is thought to be predominantly caused by hereditary factors, immune factors, environmental responses, metabolic factors, etc. (19). Previous immunological studies 
have suggested that $\mathrm{T}$ lymphocytes and keratinocytes have a critical role in the pathogenesis of skin disorders $(20,21)$. In addition, recent research on psoriasis predominantly focused on the activation of certain immune cells (22). The present study investigated haptoglobin protein and mRNA expression in psoriatic lesions in order to elucidate the relationship between haptoglobin protein and mRNA and psoriasis. The results demonstrated that the protein and mRNA expression levels of haptoglobin were markedly higher in patients with psoriasis compared with in normal control and NC samples. In addition, increased haptoglobin expression was exhibited in the Langerhans cells of psoriatic lesional skin compared with in normal skin.

According to in situ hybridization and RT-PCR, haptoglobin mRNA expression was expressed in keratinocytes of the experimental and NC groups, whereas the expression was markedly increased in the experimental group compared with in the normal control and NC groups. Immunohistochemistry and double-labeling immunofluorescence demonstrated that haptoglobin expression with heterogeneous distribution was detected in the keratinocytes of the experimental group; however, there was no haptoglobin protein expressed in the keratinocytes of the NC and normal control groups. Therefore, it may be concluded that high haptoglobin expression is closely associated with the occurrence of psoriasis.

Previous studies have demonstrated that the accelerated proliferation and differentiation of keratinocytes, angiogenesis, and increased autoreactive $\mathrm{T}$ lymphocytes are responsible for the initiation of psoriasis (23-25). Furthermore, haptoglobin has been reported to influence the activation and maturation of Langerhans cells, which implicates its pivotal function in the immune response (26).

The present study detected haptoglobin ${ }^{+}$dendritic cells in the three groups. Compared with the normal control group, the ratio of haptoglobin ${ }^{+}$Langerhans cells to total Langerhans cells was markedly increased in the experimental and NC groups. These results suggested that there may be more haptoglobin present in the Langerhans cells in lesions from patients with psoriasis. In the experimental group, small dendritic cells were observed in the middle-upper epidermis, and dendrites were short and thick. However, in the other two groups, dendritic cells were predominantly distributed in the middle and lower segments of the epidermis, and dendrites were thin and long. The results of the double-labeling immunofluorescence study confirmed that haptoglobin ${ }^{+}$dendritic cells were $\mathrm{CD} \mathrm{a}^{+}$Langerhans cells, thus indicating that haptoglobin may inhibit the maturation of Langerhans cells. This speculation is consistent with previous research, which proposed that epidermal Langerhans cells are important for cutaneous immunological responses, and $\mathrm{Hp}$ is an inhibitor that prevents Langerhans cell functional transformation in the skin (27). Dendritic cells are antigen-presenting cells that have an important role in the adaptive immune system. Dendritic cells are able to induce a primary immune response in inactive or resting naïve T lymphocytes (28). Therefore, it may be concluded that overexpression of haptoglobin leads to formation of Langerhans cell throughout the keratinocytes, which could activate $\mathrm{T}$ cells to accelerate the proliferation and differentiation of keratinocytes, thus inducing the occurrence of psoriasis.
The present study provided evidence regarding the mechanism underlying the disordered immune response in psoriasis; however, the underlying cause of haptoglobin protein and mRNA overexpression requires further research. Furthermore, the pivotal function for Langerhans cell engulfing haptoglobin also requires further research. In conclusion, haptoglobin protein and mRNA may serve as an important biomarker for the diagnosis of psoriasis. In addition, the present study offers a novel manner for the investigation of psoriasis at the mRNA and protein level.

\section{References}

1. Dubois Declercq S and Pouliot R: Promising new treatments for psoriasis. ScientificWorldJournal 2013: 980419, 2013.

2. Roberson ED and Bowcock AM: Psoriasis genetics: Breaking the barrier. Trends Genet 26: 415-423, 2010.

3. Nograles KE and Krueger JG: Anti-cytokine therapies for psoriasis. Exp Cell Res 317: 1293-1300, 2011.

4. Menter A, Gottlieb A, Feldman SR, Van Voorhees AS, Leonardi CL, Gordon KB, Lebwohl M, Koo JY, Elmets CA, Korman NJ, et al: Guidelines of care for the management of psoriasis and psoriatic arthritis: Section 1. Overview of psoriasis and guidelines of care for the treatment of psoriasis with biologics. J Am Acad Dermatol 58: 826-850, 2008.

5. Boehncke WH and Schön MP: Psoriasis. Lancet 386: 983-994 2015.

6. Palfreeman AC, McNamee KE and McCann FE: New developments in the management of psoriasis and psoriatic arthritis: A focus on apremilast. Drug Des Devel Ther 7: 201-210, 2013.

7. Nestle FO, Kaplan DH and Barker J: Psoriasis. N Engl J Med 361: 496-509, 2009.

8. Bowcock AM and Krueger JG: Getting under the skin: The immunogenetics of psoriasis. Nat Rev Immunol 5: 699-711, 2005.

9. Ko DH, Chang HE, Kim TS, Song EY, Park KU, Song J and Han KS: A review of haptoglobin typing methods for disease association study and preventing anaphylactic transfusion reaction. Biomed Res Int 2013: 390630, 2013.

10. Wassell J: Haptoglobin: Function and polymorphism. Clin Lab 46: 547-552, 2000.

11. Langlois MR and Delanghe JR: Biological and clinical significance of haptoglobin polymorphism in humans. Clin Chem 42: 1589-1600, 1996

12. Shah A, Singh H, Sachdev V, Lee J, Yotsukura S, Salgia R and Bharti A: Differential serum level of specific haptoglobin isoforms in small cell lung cancer. Curr Proteomics 7: 49-65, 2010.

13. Lin Z, Simeone DM, Anderson MA, Brand RE, Xie X, Shedden KA, Ruffin MT and Lubman DM: Mass spectrometric assay for analysis of haptoglobin fucosylation in pancreatic cancer. J Proteome Res 10: 2602-2611, 2011.

14. Fujimura T, Shinohara Y, Tissot B, Pang PC, Kurogochi M, Saito S, Arai Y, Sadilek M, Murayama K, Dell A, et al: Glycosylation status of haptoglobin in sera of patients with prostate cancer vs. benign prostate disease or normal subjects. Int J Cancer 122: 39-49, 2008.

15. Zhao ZM, Yang L and Cui B: X-ray findings and clinical analysis for newborn infants with neonatal respiratory distress syndrome. Zhong Nan Da Xue Xue Bao Yi Xue Ban 32: 1069-1074, 2007 (In Chinese).

16. Lu JY, Wu ZQ, Tan LN, Chen J, Xiang YP, Zuo CX, Huang JH and Jiang XZ: mRNA and protein expression of haptoglobin in lesions of condyloma acuminatum. Zhong Nan Da Xue Xue Bao Yi Xue Ban 32: 1020-1025, 2007 (In Chinese).

17. Li P, Gao XH, Chen HD, Zhang Y, Wang Y, Wang H, Wang Y and Xie Y: Localization of haptoglobin in normal human skin and some skin diseases. Int J Dermatol 44: 280-284, 2005.

18. Xie Y, Li Y, Zhang Q, Stiller MJ, Wang CL and Streilein JW: Haptoglobin is a natural regulator of Langerhans cell function in the skin. J Dermatol Sci 24: 25-37, 2000.

19. Buchau AS and Gallo RL: Innate immunity and antimicrobial defense systems in psoriasis. Clin Dermatol 25: 616-624, 2007.

20. Martin G, Guerard S, Fortin MM, Rusu D, Soucy J, Poubelle PE and Pouliot R: Pathological crosstalk in vitro between $T$ lymphocytes and lesional keratinocytes in psoriasis: Necessity of direct cell-to-cell contact. Lab Invest 92: 1058-1070, 2012. 
21. Zheng Y, Danilenko DM, Valdez P, Kasman I, Eastham-Anderson J, Wu J and Ouyang W: Interleukin-22, a $\mathrm{T}(\mathrm{H}) 17$ cytokine, mediates IL-23-induced dermal inflammation and acanthosis. Nature 445: 648-651, 2007.

22. Christophers E, Metzler G and Rocken M: Bimodal immune activation in psoriasis. Br J Dermatol 170: 59-65, 2014.

23. Lebwohl M: Psoriasis. Lancet 361: 1197-1204, 2003.

24. Heidenreich R, Rocken M and Ghoreschi K: Angiogenesis drives psoriasis pathogenesis. Int J Exp Pathol 90: 232-248, 2009.

25. Gudmundsdottir AS, Sigmundsdottir H, Sigurgeirsson B, Good MF, Valdimarsson $\mathrm{H}$ and Jonsdottir I: Is an epitope on keratin 17 a major target for autoreactive $\mathrm{T}$ lymphocytes in psoriasis? Clin Exp Immunol 117: 580-586, 1999.
26. Said A and Weindl G: Regulation of dendritic cell function in inflammation. J Immunol Res 2015: 743169, 2015.

27. Wang H, Gao XH, Wang YK, Li P, He CD, Xie Y and Chen HD Expression of haptoglobin in human keratinocytes and Langerhans cells. Br J Dermatol 153: 894-899, 2005.

28. Carroll-Portillo A, Cannon JL, Te Riet J, Holmes A, Kawakami Y, Kawakami T, Cambi A and Lidke DS: Mast cells and dendritic cells form synapses that facilitate antigen transfer for $\mathrm{T}$ cell activation. J Cell Biol 210: 851-864, 2015. 